\title{
Análise Custo-Volume-Lucro em uma Escola de Idiomas: um Estudo de Caso
}

\author{
Cost-Volume-Profit Analysis in a Language School: A Case Study
}

Análisis Costo-Volumen-Beneficio en una Escuela de Idiomas: Un Estudio de Caso

\begin{abstract}
Natanael Augusto Ukrainski ${ }^{1}$ natanaelukrainski@hotmail.com http://lattes.cnpq.br/5728910986063415 https://orcid.org/0000-0002-9930-8608

Willson Gerigk ${ }^{1}$ wgerigk@unicentro.br http://lattes.cnpq.br/9085562155938774 https://orcid.org/0000-0003-2144-3452

Flávio Ribeiro ${ }^{1}$ flavioribeiro@unicentro.br http://lattes.cnpq.br/9438513814847904 http://orcid.org/0000-0002-3547-9539
\end{abstract}

Universidade Estadual do Centro-Oeste, Unicentro, Brasil ${ }^{1}$

Recebido em: 03/05/2020 / Revisão: 04/07/2020 / Aprovado em: 01/08/2020

Editores responsáveis: Prof. Dr. Antônio Giovanni Figliuolo Uchôa e Prof. Dr. Jonas Fernando Petry Processo de Avaliação: Double Blind Review DOI: https://10.47357/ufambr.v2i3.7419 


\section{Resumo}

A presente pesquisa aplicou os conceitos da análise de Custo/Volume/Lucro (CVL) em um empreendimento que explora a educação de idiomas, mais especificamente, o inglês. Buscouse identificar quais as informações de caráter gerencial essas aplicações podem oferecer aos administradores da empresa. O estudo foi realizado junto a uma escola franqueada de idiomas, que atua na cidade de São José dos Pinhais-PR e que começou a operar no ano de 2017. A pesquisa caracteriza-se como descritiva, bibliográfica, documental, estudo de caso e abordagem é qualitativa e quantitativa. O estudo englobou o período de maio/2018 a abril/2019. Os resultados da pesquisa, decorrentes da aplicação da análise CVL, possibilitaram à escola conhecer: i) a margem de contribuição por aluno, em cada turma, assim como, a margem de contribuição total por turma; ii) o ponto de equilíbrio por turma, por aluno e o ponto de equilíbrio total da escola; iii) a margem de segurança por turma e a total; e iv) o grau de alavancagem operacional, inclusive mensalmente.

Palavras-chave: Análise CVL; Contabilidade Gerencial; Escola de Idiomas; Estudo de Caso.

\section{Abstract}

\section{Cost-Volume-Profit Analysis in a Language School: A Case Study}

This research applied the concepts of Cost/Volume/Profit analysis in an enterprise that explores language education, more specifically, English. We sought to identify what managerial information these applications can offer to company administrators. The study was carried out at a franchised language school, which operates in the city of São José dos Pinhais-PR and which started operating in 2017. The research is characterized as descriptive, bibliographic, documentary, case study and approach is qualitative and quantitative. The study covered the period from May / 2018 to April / 2019. The results of the research, resulting from the application of the CVL analysis, enabled the school to know: i) the contribution margin per student, in each class, as well as the total contribution margin per class; ii) the breakeven point per class, per student and the total breakeven point of the school; iii) the safety margin per class and the total; and iv) the degree of operational leverage, including monthly.

Keywords: CVL analysis; Management accounting; Language school; Case study.

\section{Análisis Costo-Volumen-Beneficio En Una Escuela De Idiomas: Un Estudio De Caso}

\section{Resumen}

Esta investigación aplicó los conceptos de análisis de Coste/Volumen/Beneficio en una empresa que explora la enseñanza de idiomas, más específicamente, del inglés. Intentamos identificar qué información gerencial pueden ofrecer estas aplicaciones a los administradores de la empresa. El estudio se llevó a cabo en una escuela de idiomas franquiciada, que opera en la ciudad de São José dos Pinhais-PR y que comenzó a operar en 2017. La investigación se caracteriza por ser descriptiva, bibliográfica, documental, estudio de caso y enfoque es cualitativo y cuantitativo. El estudio cubrió el período de mayo / 2018 a abril / 2019. Los resultados de la investigación, resultantes de la aplicación del análisis CVL, permitieron a la escuela saber: i) el margen comercial por estudiante, en cada clase, así como el margen 
Análise Custo-Volume-Lucro em uma Escola de Idiomas: um Estudo De Caso

comercial total por clase; ii) el punto de equilibrio por clase, por estudiante y el punto de equilibrio total de la escuela; iii) el margen de seguridad por clase y el total; y iv) el grado de apalancamiento operativo, incluido el mensual.

Palabras clave: análisis CVL; Contabilidad Gerencial; Escuela de idiomas; Estudio de caso. 


\section{INTRODUÇÃO}

O uso do idioma inglês vem crescendo consideravelmente nos últimos tempos devido a globalização, no meio empresarial isso foi impulsionado em razão da internacionalização comercial entre os países, fato que tem contribuído para que a língua inglesa seja adotada como o idioma mais comum usado para se fazer negócios entre os países (Santos, 2005). O inglês é o idioma mundial dos negócios, da cultura e das ciências, é a língua mais falada do mundo na soma de falantes nativos e pessoas que a usam como segundo idioma (Estadão, 2017).

Segundo Wernke, Faccenda e Junges (2017) aspectos como a facilidade de acesso à internet e a globalização econômica tem incentivado a procura pelo aprendizado de outros idiomas no Brasil. Esse interesse por outros idiomas é um fator que estimula o surgimento de escolas desse ramo no país, o que acaba por acirrar a concorrência nesse nicho de mercado.

Ross e Rosemary (2012) afirmam que devido à necessidade de se aprender outros idiomas inúmeros empresários acabam abrindo escolas para que possam ter um lucro nessa área. Porém, Filion (1999) alerta que, abrir um negócio numa área em que pode se dizer que está em crescimento não é garantia de se ter lucro.

Para Durieux, Beuren, Sousa e Raupp (2003), os sistemas de franquias têm atraído mais e mais empreendedores, surgindo com uma alternativa de negócio próprio, sendo o setor de educação um dos ramos que possui o maior número de franqueados.

Assim, para fazer frente a esse aumento da competição cabe aos gestores dessas instituições de ensino, franqueadas ou não, gerenciarem seus custos de modo a otimizar o resultado (Wernke, Faccenda \& Junges, 2017).

Para este fim, de formação de informações de cunho gerencial sobre o empreendimento, a contabilidade utiliza-se das técnicas de levantamento e análises desenvolvidos pela contabilidade gerencial, que tem por enfoque os usuários internos, em quaisquer níveis da administração, que necessitam de informações contábeis para o procedimento de planejamento, para a gestão das operações e subsidiar o processo de tomada de decisão (Padoveze, 2011).

Dentre as técnicas utilizadas pela contabilidade gerencial está a análise de custo/volume/lucro (CVL). Hansen e Mowen (2001) caracterizam a análise CVL como um instrumento valioso para identificar a extensão e magnitude de um problema econômico pelo qual a empresa esteja passando e ajudá-la a encontrar as soluções necessárias.

Wernke, Faccenda e Junges (2017) argumentam que na maioria das micro e pequenas empresas determinadas ferramentas gerenciais não deveriam deixar de serem utilizadas, como o caso da análise CVL. Estudos de Ferronatto (2014), Mantovani (2016), mostram que a análise CVL está sendo utilizada em redes de ensino, com objetivo de melhorar tanto a eficiência com também a lucratividade das operações das escolas.

Nesse enfoque, aplicação da análise custo/volume/lucro em empresas da área de ensino, o presente estudo orienta-se pela seguinte questão de pesquisa: quais aspectos qualitativos e quantitativos a análise CVL propicia quando aplicada em uma escola franqueada de idiomas? 
O objetivo central do presente estudo é identificar quais e de que forma as informações de caráter gerencial geradas pela análise custo/volume/lucro podem ser utilizadas pelos administradores de um empreendimento que explora a educação de idiomas, mais especificamente, o inglês.

A relevância acadêmica desta pesquisa pauta-se sobre a ampliação da aplicação prática da análise CVL em empresas prestadoras de serviços, o que contribuiu para avançar o entendimento quanto especificidade que a aplicação da técnica gerencial pode revelar no segmento econômico da prestação de serviços de ensino. Socialmente o presente estudo reveste de importância em razão da representatividade do segmento de serviços junto a economia nacional, bem como, o porte da empresa estudada que envolve a realidade de grande parte das empresas brasileiras, portanto, estudos voltados para esse segmento da atividade econômica e que envolvam micro e pequenas empresas certamente justificam o caráter social da presente pesquisa.

Após essa introdução, na sequência aborda-se o referencial teórico do estudo, na terceira seção a metodologia é descrita, os resultados da pesquisa são apresentados e discutidos na quarta seção, por fim, as considerações sobre o estudo são evidenciadas.

\section{REFERENCIAL TEÓRICO}

A presente pesquisa tem com enfoque a análise custo/volume/lucro (CVL), porém, para a aplicação de tal ferramenta gerencial a presente fundamentação teórica abordou conceitos relacionados com a contabilidade gerencial e os fundamentos da análise CVL.

\subsection{Contabilidade gerencial}

A contabilidade gerencial é o segmento da ciência contábil que congrega o conjunto de informações necessárias à administração que complementam as informações existentes na Contabilidade Financeira. A contabilidade gerencial busca atender os usuários internos, em quaisquer níveis da administração, que necessitam de informações contábeis para o processo de planejamento e controle das operações e para subsidiar a tomada de decisão (Padoveze, 2011).

A contabilidade gerencial pode ser definida como um enfoque especial conferido as várias técnicas e procedimentos contábeis conhecidos e tratados na contabilidade financeira, na contabilidade de custos, na análise financeira e de balanços etc., preocupa-se com detalhes da entidade como um todo e também de partes da empresa como: seus produtos e/ou serviços, departamentos, setores etc. (Horngren, Sundem \& Stratton, 2004).

A contabilidade gerencial se caracteriza pela liberdade e autonomia de critérios na criação de relatórios para disponibilização de informações à gestão do empreendimento, diferente da contabilidade financeira que se utiliza de normas nacionais internacionais (Marion, 2011).

\subsection{Análise custo/volume/lucro (CVL)}


A análise CVL é uma ferramenta valiosa para identificar a extensão e magnitude de um problema econômico pelo qual a empresa esteja passando e ajudá-la a encontrar soluções necessárias (Hansen \& Mowen, 2001).

Segundo Maher (2001), o custo/volume/lucro (CVL) acabou se tornando uma ferramenta que auxilia os gestores no que se refere à tomada de decisões em relação ao nível de operação dos negócios. Uma das funções da análise de CVL é de determina a influência no lucro, provocada por alterações nas quantidades vendidas e nos custos (Bornia, 2010).

Segundo Warren, Reeve e Fees (2001), a análise de custo/volume/lucro (CVL) pode ser descrita como um exame sistemático das relações entre o preço de venda, volume da produção e de venda. A análise CVL engloba conceito de Margem de Contribuição, Ponto de Equilíbrio, Margem de Segurança e Alavancagem Operacional (Souza \& Diehl, 2009).

A análise CVLé uma das análises mais eficientes que a contabilidade dispõe. Na Figura 1 consta a formação técnica da análise CVL.

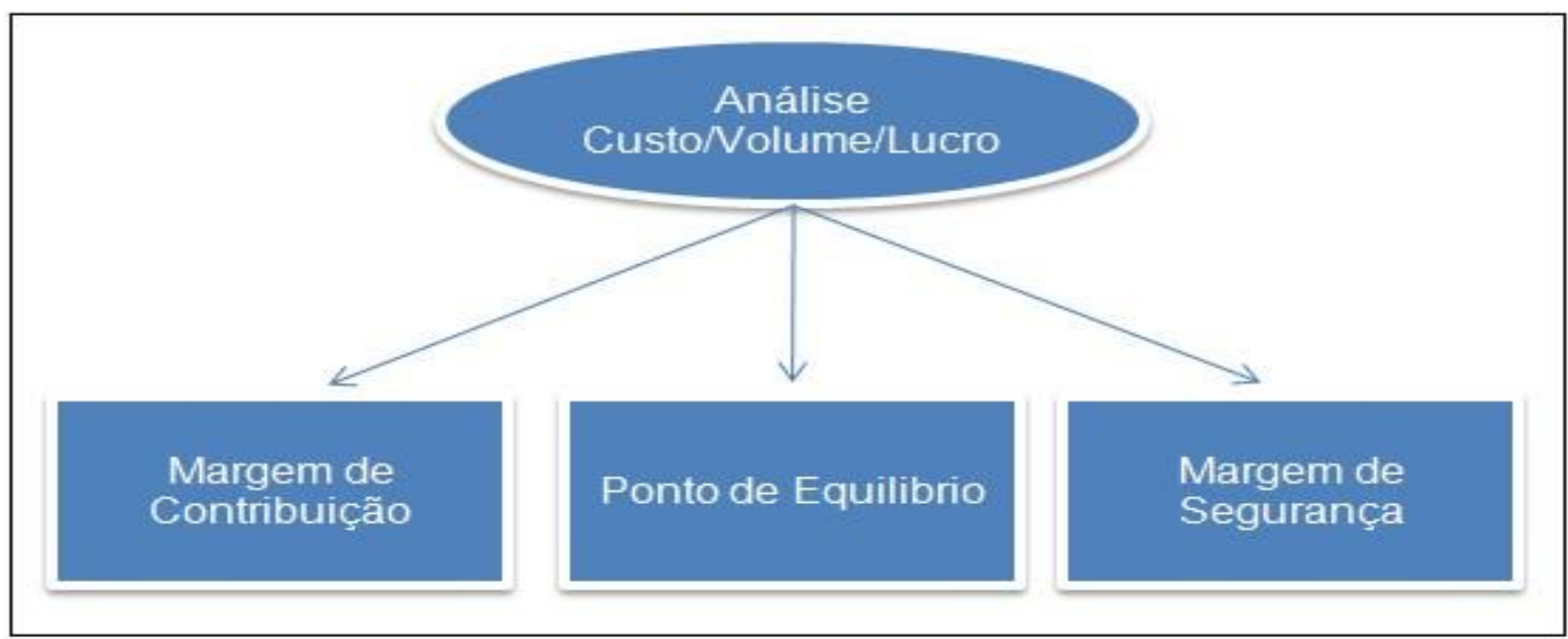

Figura 1. Componentes da análise custo/volume/lucro

Fonte: Warren, C. S., Reeve, J. M., \& Fees, P. E. (2001). Contabilidade gerencial. 2.ed. São Paulo: Pioneira Thomson Learning.

Horngren, Foster e Datar (2004) afirmam que a análise CVL precisa de certos pressupostos para dar validade aos seus resultados. As hipóteses básicas requeridas para uma correta estimação e compreensão do comportamento das variáveis envolvidas nessa análise são:

a) Mudanças nas receitas e custos ocorrem devido a mudanças no número de unidades produzidas e vendidas;

b) Os custos totais devem ser separados em custos fixos, os quais não variam conforme o nível de produção, e em custos variáveis, que variam de acordo com a produção;

c) O preço de venda, os custos fixos e as variáveis são conhecidos e permanecem constantes dentro do período analisado;

d) As receitas e os custos variáveis são lineares com relação à produção dentro de um período de análise;

e) A análise cobre um único produto ou, quando da existência de múltiplos produtos, a proporção de venda desses produtos no todo se manterá constante quando da alteração da quantidade total de unidades vendidas; e 
f) Todas as receitas e custos podem ser agregados e comparados sem levar em consideração o valor do dinheiro no tempo.

Segundo Machuga (2012) a análise CVL pode ser uma ferramenta externamente útil para o potencial de sucesso de um empreendimento, pois, utilizando-se de simulações dinâmicas permite a rápida determinação dos impactos de pressupostos diferentes para entender como as mudanças em preços e custos afetam os resultados da empresa.

Dalmacio, Lopes, Rangel e Teixeira (2013) afirmam que “[...] a literatura a respeito da análise do custo-volume-lucro trata apenas de aplicações dos conceitos teóricos em empresas comerciais e industriais, não abordando as prestadoras de serviços". Com o enfoque nas empresas prestadoras de serviços, estudos estão aplicando a análise CVL com o objetivo de analisar as vantagens e limitações dessa ferramenta gerencial quanto no ramo de serviços.

O estudo de Ferronato (2014) nessa linha, analisou a aplicação da análise CVL em organização de ensino (educação infantil, séries iniciais, séries finais e ensino médio), um dos achados foi de que a análise permitiu determinar a situação de cada um dos serviços na composição do mix de venda e sua representação na rentabilidade da empresa. Também, foi possível conhecer o desempenho individual de cada serviço prestado e definir possíveis ações estratégicas, inclusive no que se refere a avaliação de metodologia de precificação dos serviços.

Wernke, Faccenda e Junges (2017) utilizaram a análise custo/volume/lucro em uma escola de idiomas com o objetivo de identificar as informações gerenciais que essa técnica gerencial oferece. Os resultados propiciaram aos administradores da entidade a obtenção de diversas informações de cunho gerencial que não dispunham até então, como: a rentabilidade das turmas, a contribuição das turmas para com o resultado do período, conhecimento do ponto de equilíbrio e da margem de segurança das operações da escola e por turma.

Gama, Jesus, Loureiro, Silva e Xaviar (2019) aplicaram a CVL em uma escola de prestação de serviços que oferta cursos de qualificação profissional. O emprego da análise CVL junto aos dados da empresa trouxe o conhecimento detalhado de seus custos, mostrando claramente em que foram aplicados os valores gastos mensalmente. Com a apuração dos indicadores de ponto de equilíbrio, depreciação, custo variável e fixo, despesas, margem de contribuição e margem de segurança evidenciou-se que esses indicadores são importantes aliados às tomadas de decisões o que possibilitou à empresa realizar, no final do período, uma análise crítica de seus custos e vendas favorecendo uma visão ampla do negócio, evidenciando a importância do detalhamento dos custos como forma de melhorar os resultados futuramente.

Estudos empíricos, igual ao proposto, realizados com empresas prestadoras de serviços na área de ensino têm confirmado os benefícios da aplicação da análise CVL para melhorar a qualidade das informações de cunho gerencial nos empreendimentos estudados, e desta forma, qualificar as tomadas de decisões no âmbito das organizações.

\subsubsection{Margem de contribuição}

Para Wernke (2010), a margem de contribuição é uma expressão designada a um valor resultante de venda de uma unidade após serem deduzidos, dos preços de vendas os custos e despesas variáveis. A Figura 2 exemplifica a Margem de Contribuição. 


\begin{tabular}{|l|}
\hline Produtos/Serviços \\
\hline Receita de vendas \\
\hline (-) Custos variáveis dos produtos vendidos \\
\hline (-) Despesas variáveis de vendas \\
\hline (=) Margem de contribuição dos produtos \\
\hline
\end{tabular}

Figura 2. Margem de contribuição

Fonte: Megliorini, E. (2011). Custos análise e gestão. 3. ed. São Paulo: Pearson Prentice Hall.

Martins (2010) a define a margem de contribuição como a diferença entre o preço de venda e o custo variável de cada produto, é o valor que cada unidade efetivamente traz à empresa de sobra entre sua receita e o custo que de fato provocou. Em vista disso, a margem de contribuição se caracteriza como o valor que cada unidade contribui, para cobrir os custos fixos (Horngren, Sundem \& Stratton, 2004). Conforme Wernke (2010), a margem de contribuição é o valor resultante da venda de uma unidade após serem deduzidos, do preço de venda, os custos e despesas variáveis. Segundo Bertó e Beulke (2006), pelo meio da margem de contribuição pode-se perceber a viabilidade de um produto ou serviço no mercado.

Segundo Cruz (2011), a margem de contribuição unitária é uma das principais medidas de desempenho de um produto ou serviço, visto que, indica o quanto este contribui para o pagamento dos gastos apurados no período, razão pela qual, se a margem de contribuição apresentar um resultado positivo pode-se dizer que o produto/serviço apresenta viabilidade financeira.

\subsubsection{Ponto de equilíbrio}

Para Bornia (2010), o ponto de equilíbrio é um indicador que mostra a quantidade mínima que precisa ser produzida e vendida para que a empresa não contabilize prejuízo. O ponto de equilíbrio se caracteriza de uma forma contábil, econômica e financeira, têm por finalidade mostrar a quantidade mínima de produtos que a empresa deve vender para que não haja um prejuízo (Martins, 2003).

O ponto de equilíbrio serve para mensurar onde termina o seu prejuízo e começa o seu lucro, e vice-versa. Alcança-lo significa obter capital suficiente para pagar todas as despesas variáveis, mês a mês (Wernke, Faccenda \& Junges, 2017).

A Figura 3 exemplifica os conceitos que são usados na análise CVL, definindo o ponto de equilíbrio, custos fixos e variáveis, receitas e o lucro. O ponto de equilíbrio define o ponto no qual o valor das receitas é igual ao valor dos custos e despesas, o que estiver acima dele é considerado como lucro, e o que estiver abaixo prejuízo, ou seja, é o número mínimo de unidades que a empresa precisa vender para cobrir seus custos e despesas. 


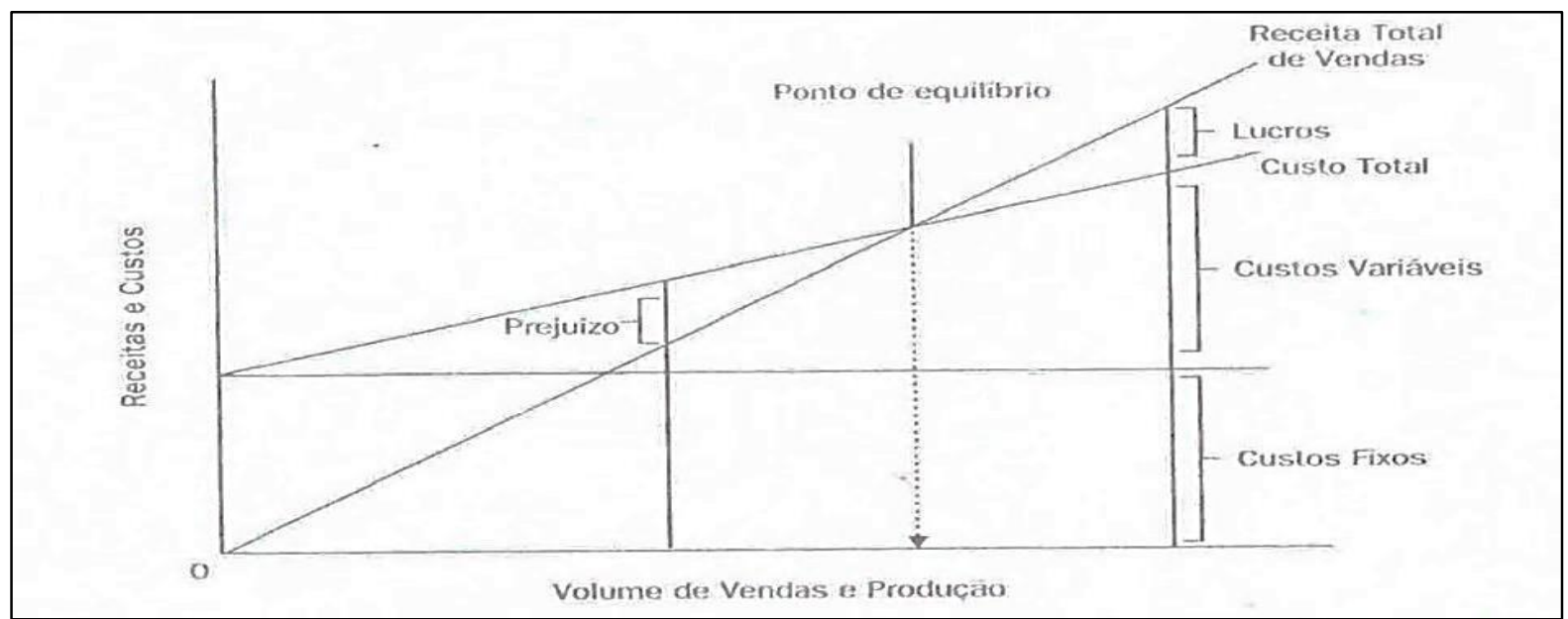

Figura 3. Gráfico do ponto de equilíbrio

Fonte: Atkinson, A. A., Banker, R. D, Kaplan; R. S., \& Young, S. M. (2000). Contabilidade gerencial. São Paulo: Atlas.

Segundo Iudícibus e Marion (1999), os custos fixos são aqueles que se mantêm inalterados, são os custos que não dependem das variações de atividades ou das vendas realizadas. Para Martins (2010) um exemplo de custo fixo, é o aluguel da fábrica, independentemente, de aumento ou diminuições, naquele mês, do volume de produção.

Os custos variáveis, entretanto, são os que variam na mesma proporção das variações ocorridas no volume de produção ou outra medida de atividade (Iudícibus \& Marion. 1999). Martins (2010) define custos variáveis como sendo aqueles que variam de acordo com o volume de produção, um exemplo destes, seriam os materiais que são utilizados diretamente na produção, como são diretamente proporcionais ao volume, variam de acordo com volume produzido.

\subsubsection{Margem de segurança}

Segundo Crepaldi (2010), a margem de segurança é o valor de vendas que supera o valor do ponto de equilíbrio. E com isso pode-se determinar volume de receitas que a empresa deverá ter para suprir suas despesas, tanto fixas como variáveis. Quanto maior for a margem de segurança, maior a capacidade de geração de lucro e também maior a segurança de que a empresa não incorrerá em prejuízo (Santos, 2011).

Para Bruni e Famá (2010), a margem de segurança é o índice que consiste na quantia das vendas que excedem o ponto de equilíbrio da empresa. Isso mostra o quanto as vendas podem cair sem que a empresa contabilize prejuízo. Quanto maior for a margem de segurança, maior a capacidade de geração de lucro e, também maior a segurança de que a empresa não incorrerá em prejuízo (Santos, 2011).

O principal objetivo da margem de segurança é mostrar para o gestor qual produto ou serviço que está gerando lucro para sua empresa e, também, qual é o percentual que poderá reduzir em produção ou em faturamento, caso seja necessário, para dedicar-se no desenvolvimento de outros produtos ou serviços (Padoveze, 2005). 


\subsubsection{Grau de alavancagem operacional}

Segundo Perez, Oliveira e Costa (2003), a alavancagem operacional ocorre quando o crescimento do lucro é maior que o crescimento das vendas, isso quer dizer que uma força nas vendas gera um impulso maior nos lucros.

Para Matarazzo (2003) a alavancagem operacional mede a sensibilidade da variação percentual do lucro sobre de vendas em função da variação do percentual do volume de vendas, devido a isso, quanto maior for o valor do grau de alavancagem operacional (GAO) mais sensível será a variação do lucro sobre as vendas.

A alavancagem operacional significa a possibilidade de acréscimo do lucro total, pelo aumento da quantidade produzida e vendida, busca maximizar o uso dos custos e despesas fixas. A alavancagem operacional resulta da margem de contribuição, significa que ela procede do impacto dos custos e das despesas variáveis sobre o preço de venda unitário e dos valores dos custos e das despesas fixas (Padoveze, 2005). A alavancagem operacional é a medida do grau de sensibilidade do lucro líquido às variações percentuais das vendas, funciona como um multiplicador: se ela é alta, um pequeno aumento percentual nas vendas pode produzir um grande aumento percentual no lucro líquido (Garrison \& Noreen, 2001).

O Grau de Alavancagem Operacional existente numa empresa a um dado nível de vendas pode ser medido pela equação 1 :

$$
\mathrm{GAO}=\frac{\text { Margem de Contribuição }}{\text { Lucro Líquido Operacional }}
$$

Portanto, podemos definir o GAO (grau de alavancagem operacional) como sendo uma ferramenta que mede os efeitos provocados sobre o lucro operacional pelas variações ocorridas nas vendas. Utiliza-se o GAO para apontar um aumento ou uma diminuição no lucro operacional, a partir das mudanças ocorridas no volume de vendas (Padoveze, 2005).

\section{METODOLOGIA}

A classificação metodológica desta pesquisa é descritiva, sendo sua abordagem qualitativa e quantitativa, com a utilização de pesquisa bibliográfica, estudo de caso, documental e com estatística simples. O estudo coletou e analisou dados contábil-financeiros de uma escola de idioma para descrever, por meio dos fundamentos da análise de custo/volume/lucro (CVL), seus resultados no período de maio/2018 a abril/2019.

A pesquisa bibliográfica foi empregada, neste estudo, para subsidiar teoricamente a definição dos elementos que integram a análise custo/volume/lucro (CVL), necessários para o desenvolvimento da pesquisa proposta.

Usou-se pesquisa documental para coletar os dados necessários, junto à escola de idiomas analisada, para a aplicação da análise CVL. Os dados contábil-financeiros foram coletados junto ao sistema contábil da escola e constam da Tabela 1. 


\section{Tabela 1}

\section{Pesquisa documental realizada na pesquisa}

\begin{tabular}{|l|l|}
\hline \multicolumn{1}{|c|}{ Dados coletados } & \multicolumn{1}{c|}{ Documentos contábeis analisados } \\
\hline Valor das mensalidades & Balancetes de verificação mensais e Demonstrações mensais do resultado (DR) \\
\hline Impostos materiais & Balancetes de verificação mensais e Demonstrações mensais do resultado (DR) \\
\hline $\begin{array}{l}\text { Custos } \begin{array}{l}\text { Demonstrativos mensais de despesas, Balancetes de verificação mensais e } \\
\text { didáticos }\end{array} \\
\text { Demonstrações mensais do resultado (DR) }\end{array}$ \\
\hline Despesas administrativas operacionais & $\begin{array}{l}\text { Demonstrativos mensais de despesas, Balancetes de verificação mensais e } \\
\text { Demonstrações mensais do resultado (DR) }\end{array}$ \\
$\begin{array}{l}\text { Demonstrativos mensais de despesas, Balancetes de verificação mensais e } \\
\text { Demonstrações mensais do resultado (DR) }\end{array}$ \\
\hline
\end{tabular}

Fonte: Dados da pesquisa (2020)

Os dados sobre a quantidade de alunos frequentes e outros referentes a forma de funcionamento da escola foram obtidos junto a coordenação geral da instituição.

A pesquisa quali/quanti tratou os dados necessários para a aplicação da análise CVL na escola de idiomas avaliada, com o objetivo de destacar quais informações geradas podem auxiliar na gestão do empreendimento.

Segundo Gil (2008) o estudo de caso pode ser definido como uma análise detalhada de um ou mais objetos de pesquisa, permitindo o aprofundamento do estudo com o objetivo de ampliar o conhecimento do elemento avaliado.

$\mathrm{Na}$ presente pesquisa o estudo de caso foi desenvolvido junto a uma escola franqueada de idiomas, situada na cidade de São José dos Pinhais - PR. Os dados coletados foram relativos às receitas, aos custos e as despesas das atividades de ensino da entidade, e serviram para a aplicação das técnicas da análise de CVL. A coleta foi feita junto ao sistema contábil da escola no período de maio/2018 a abril/2019. Também foram obtidas informações complementares sobre o funcionamento da escola e dúvidas sobre os dados coletados junto à coordenação geral da instituição.

A presente pesquisa orienta-se e segue a estrutura de análise do estudo de Wernke, Faccenda e Junges (2017), que utilizaram a análise custo/volume/lucro em uma escola de idiomas com o objetivo de identificar as informações gerenciais que essa técnica gerencial oferece. A motivação para usar tal estudo deve-se ao formato de análise proposta e pela possibilidade de sua aplicação em empresas do segmento de serviços que atuem com receitas vinculadas à cobrança de mensalidade.

\section{RESULTADOS E DISCUSSÕES DO ESTUDO}

Na seção são apresentados os resultados do desenvolvimento da pesquisa, que aplicou a análise CVL em uma escola franqueada de idiomas (inglês), situada na cidade de São José dos Pinhais - PR, e as análises compreenderam os meses de maio/2018 a abril/2019.

Os primeiros dados levantados foram sobre as turmas em funcionamento entre maio/2018 a abril/2019. Na Tabela 2 constam as turmas, o valor das mensalidades e o custo do material escolar por aluno. 
Tabela 2

Dados iniciais sobre as turmas - maio/2018 a abril/2019

\begin{tabular}{l|c|c}
\hline \multicolumn{1}{c|}{ Turmas } & Valor Mensalidade R $\$$ & Material por Aluno R $\$$ \\
\hline Adults + Hyper & 311,50 & 50,00 \\
Adults & 311,50 & 50,00 \\
Hyper & 255,58 & 30,83 \\
Teens & 251,50 & 22,50 \\
\hline
\end{tabular}

Fonte: Dados da pesquisa (2020).

No período estudado a escola contou com 4 níveis de turma: Adults + Hyper, Adults, Hyper e Teens. Com os dados preliminares do valor das mensalidades, dos custos com material escolar e as informações sobre os impostos incidentes foi confeccionada a Tabela 3, que contém a margem de contribuição por aluno.

Tabela 3

Margem de contribuição por aluno e por turma - maio/2018 a abril/2019

\begin{tabular}{l|c|c|c|c|c}
\hline Turma & $\begin{array}{c}\text { Valor } \\
\text { Mensalidade (R\$) }\end{array}$ & $\begin{array}{c}\text { Imposto por } \\
\text { aluno } \\
(\mathrm{R} \$)\end{array}$ & $\begin{array}{c}\text { Material por } \\
\text { aluno } \\
(\mathrm{R} \$)\end{array}$ & $\begin{array}{c}\text { Margem de } \\
\text { Contribuição por } \\
\text { aluno (R\$) }\end{array}$ & $\begin{array}{c}\text { Margem de } \\
\text { Contribuição } \\
\text { por aluno em \% }\end{array}$ \\
\hline Adults + Hyper & 311,50 & 6,23 & 50,00 & 255,27 & $81,95 \%$ \\
Adults & 311,50 & 6,23 & 50,00 & 255,27 & $81,95 \%$ \\
Hyper & 255,58 & 5,11 & 30,83 & 219,64 & $85,94 \%$ \\
Teens & 251,50 & 5,03 & 22,50 & 223,97 & $89,05 \%$ \\
\hline
\end{tabular}

Fonte: Dados da pesquisa (2020).

A margem de contribuição por aluno foi calculada, para todas as turmas, da seguinte forma, com base na turma Adults + Hyper: do valor da mensalidade (R $\$ 311,50)$ foram subtraídos os valores do imposto incidente sobre a mensalidade $(\mathrm{R} \$ 6,23)$, conforme alíquota repassada pela escola, e os custos com materiais didáticos $(\mathrm{R} \$ 50,00)$ esses materiais são cobrados todos os meses dos estudantes junto com a mensalidade. A margem de contribuição unitária por aluno, em valores monetários, da turma foi de $\mathrm{R} \$ 255,27(311,50-6,23-50,00=255,27)$. E a margem de contribuição em percentual (\%) por estudante contabilizou 81,95\% (255,27/311,50 x 100).

Os resultados da Tabela 3 indicaram que as turmas Adults + Hyper e Adults foram as que registraram maiores margens de contribuição, ambas, com $\mathrm{R} \$ 255,27$. Entretanto, quanto à margem de contribuição em \%, a turma Teens foi a que apresentou maior percentual 89,05\%, seguida da Hyper com 85,94 e pôr fim a Adults + Hyper e a Adults com 81,95\%.

Baseando-se nas margens de contribuições unitárias de cada turma (Tabela 3), calcularam-se as margens de contribuições totais por turma, no período de maio/2018 a abril/2019. Para tanto, foram considerados os alunos regulares em cada um dos meses em cada uma das turmas, valores constam na Tabela 4. 
Tabela 4

Margem de contribuição total por turma - maio/2018 a abril/2019

\begin{tabular}{l|c|r|r|r|r|r|r}
\hline Turma & $\begin{array}{c}\text { Quantidade } \\
\text { de alunos }\end{array}$ & $\begin{array}{c}\text { Valor } \\
\text { Mensalidade } \\
(\mathrm{R} \$)\end{array}$ & $\begin{array}{c}\text { Valor Total } \\
\text { Mensalidades } \\
\text { por turma } \\
(\mathrm{R} \$)\end{array}$ & $\begin{array}{c}\text { Imposto por } \\
\text { turma } \\
(\mathrm{R} \$)\end{array}$ & $\begin{array}{c}\text { Material por } \\
\text { turma } \\
(\mathrm{R} \$)\end{array}$ & $\begin{array}{c}\text { Margem de } \\
\text { Contribuição } \\
\text { por turma } \\
\text { (R\$) }\end{array}$ & $\begin{array}{c}\text { Margem de } \\
\text { Contribuição } \\
\text { em \% do } \\
\text { total }\end{array}$ \\
\hline Adults + & & & & & & & \\
Hyper & 827 & 311,50 & $257.610,50$ & $5.152,21$ & $41.350,00$ & $211.108,29$ & $49,23 \%$ \\
Adults & 736 & 311,50 & $229.264,00$ & $4.585,28$ & $36.800,00$ & $187.878,72$ & $43,82 \%$ \\
Hyper & 50 & 255,58 & $12.779,00$ & 255,58 & $1.541,50$ & $10.981,92$ & $2,56 \%$ \\
Teens & 84 & 251,50 & $21.126,00$ & 422,52 & $1.890,00$ & $18.813,48$ & $4,39 \%$ \\
\hline Total... & 1.697 & & $520.779,50$ & $10.415,59$ & $81.581,50$ & $428.782,41$ & $100,00 \%$ \\
\hline
\end{tabular}

Fonte: Dados da pesquisa (2020).

Para determinar os valores torais multiplicou-se os valores unitários pelo número de alunos regulares de cada uma das turmas. Os cálculos indicaram que a margem de contribuição total da turma Adults + Hyper foi de R $\$ 211.108,29$, de maio/2018 a abril/2019, a da Adults atingiu $\mathrm{R} \$ 187.878,72$, a Hyper $\mathrm{R} \$ 10.981,92$ e a Teens contabilizou margem de contribuição total de $\mathrm{R} \$ 18.813,48$.

Diante da margem de contribuição total das quatro turmas de $\mathrm{R} \$ 428.782,41$, no período avaliado, calculou-se a participação percentual de cada uma das turmas para formar esse montante. Constatou-se que as turmas com as maiores quantidades de alunos são as que mais contribuem para o montante total, ou seja, a Adults + Hyper contribuiu com 49,23\% da margem de contribuição total e a Adults com 43,82\%, juntas totalizaram 93,05\% do montante total.

Na sequência passou para a determinação do ponto de equilíbrio total da escola e também por turma, no período de maio/2018 a abril/209. Com base no sistema contábil da instituição foram coletadas as despesas e custos do período, após, separou-se as despesas administrativas e operacionais, as quais contam, mensalmente, nas Tabelas 5 e 6 , respectivamente.

Tabela 5

Despesas administrativas mensais - maio/2018 a abril/2019

\begin{tabular}{|c|c|c|c|c|c|c|c|c|c|c|c|c|}
\hline Despesas Administrativas & $\mathrm{mai} / 18$ & jun/18 & $\mathrm{jul} / 18$ & $\mathrm{ago} / 18$ & set $/ 18$ & out $/ 18$ & nov/18 & $\operatorname{dez} / 18$ & $\mathrm{jan} / 19$ & fev/19 & $\mathrm{mar} / 19$ & $a b r / 19$ \\
\hline Luz & 160,00 & 130,81 & 128,73 & 138,43 & 169,12 & 159,90 & 170,31 & 161,75 & 0,00 & 0,00 & 247,69 & 181,77 \\
\hline Água & 160,14 & 154,11 & 154,65 & 154,65 & 170,00 & 157,75 & 157,53 & 170,00 & 137,19 & 0,00 & 137,19 & 137,19 \\
\hline Imóvel - Aluguel / Seguro / IPTU & 0,00 & 0,00 & $5.959,30$ & $5.859,71$ & $4.488,08$ & $4.488,08$ & $4.484,88$ & $8.828,10$ & $4.123,63$ & $4.123,63$ & $4.414,31$ & $4.123,63$ \\
\hline Despesas com Administração & $1.836,00$ & $1.830,00$ & $1.062,00$ & $2.027,40$ & $1.968,00$ & $12.031,00$ & $2.030,00$ & $1.969,00$ & $6.200,00$ & $4.412,25$ & $4.455,00$ & $2.780,00$ \\
\hline Despesa com Segurança & $1.698,50$ & $1.698,50$ & $1.698,50$ & $1.773,50$ & $1.777,95$ & $1.398,50$ & $1.777,50$ & 365,50 & 123,50 & 939,50 & 939,50 & 871,50 \\
\hline Reforma / Manutenção Imóvel & 100,00 & 0,00 & 0,00 & 0,00 & 0,00 & 0,00 & 0,00 & 0,00 & 0,00 & 500,00 & 0,00 & 0,00 \\
\hline Supermercado e Similares & 0,00 & 75,75 & 0,00 & 194,00 & 0,00 & 0,00 & 97,84 & 0,00 & 120,00 & 81,11 & 224,07 & 0,00 \\
\hline Telefone / Internet & 0,00 & 220,61 & 242,10 & 182,08 & 182,50 & 133,41 & 179,99 & 189,00 & 0,00 & 0,00 & 288,96 & 179,99 \\
\hline Confraternização & 0,00 & 0,00 & 62,40 & 920,00 & 26,00 & 0,00 & 0,00 & 0,00 & 0,00 & 0,00 & 0,00 & 0,00 \\
\hline Despesas Diversas & 212,59 & 0,00 & 25,97 & 0,00 & 65,00 & 0,00 & $1.248,75$ & 0,00 & $2.920,00$ & 914,10 & 557,97 & 680,70 \\
\hline 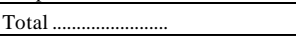 & $4.167,23$ & $4.109,78$ & $9.333,65$ & $11.249,77$ & $8.846,65$ & $18.368,64$ & $10.146,80$ & $11.683,35$ & $13.624,32$ & $10.970,59$ & $11.264,69$ & $8.954,78$ \\
\hline
\end{tabular}

Fonte: Dados da pesquisa (2020). 
Tabela 6

Despesas operacionais mensais - maio/2018 a abril/2019

\begin{tabular}{|c|c|c|c|c|c|c|c|c|c|c|c|c|}
\hline Despesas Operacionais & $\mathrm{mai} / 18$ & jun $/ 18$ & $\mathrm{ju} / / 18$ & $\mathrm{ago} / 18$ & set/18 & out $/ 18$ & nov/18 & $\operatorname{dez} / 18$ & $\mathrm{jan} / 19$ & fev/19 & $\mathrm{mar} / 19$ & $a b r / 19$ \\
\hline Despesas com Pedagógico (Salário) & $5.580,00$ & $5.528,00$ & $5.859,00$ & $4.546,00$ & $7.207,00$ & $6.743,00$ & $6.478,00$ & $5.462,00$ & $5.519,80$ & $4.236,00$ & $7.768,88$ & $7.119,00$ \\
\hline INSS & 754,82 & 804,76 & 681,55 & 636,67 & 634,43 & 634,43 & 757,49 & 794,17 & 0,00 & 0,00 & 0,00 & 0,00 \\
\hline FGTS & 608,66 & 527,71 & 534,21 & 516,82 & 518,82 & 518,82 & 641,88 & 915,69 & 870,21 & 651,35 & 639,78 & $1.107,00$ \\
\hline Vale Transporte (Compra) & 400,00 & 202,00 & 574,30 & 408,00 & 622,00 & 408,00 & $1.643,00$ & 289,00 & 837,00 & $1.661,00$ & 148,20 & 890,50 \\
\hline $13^{\circ}$ Salário & 0,00 & 0,00 & 0,00 & 0,00 & 0,00 & 0,00 & $3.185,98$ & $3.771,92$ & 0,00 & 0,00 & 0,00 & 0,00 \\
\hline Rescisão Trabalhista & 0,00 & $3.967,74$ & $1.522,93$ & 0,00 & 0,00 & 0,00 & 0,00 & 0,00 & 0,00 & 0,00 & 0,00 & $3.574,83$ \\
\hline Royalties (Franquia British) & $1.100,00$ & $1.100,00$ & $1.100,00$ & $1.100,00$ & $1.100,00$ & $1.100,00$ & $1.100,00$ & $1.100,00$ & $1.183,05$ & $1.183,05$ & $1.183,05$ & $1.183,05$ \\
\hline Certificados (Alunos) & 0,00 & 0,00 & 40,00 & 0,00 & 0,00 & 0,00 & 120,00 & 0,00 & 0,00 & 0,00 & 0,00 & 60,00 \\
\hline Despesas com Propaganda & $1.676,00$ & 325,00 & 0,00 & $1.102,50$ & $1.694,50$ & $1.808,50$ & $1.511,00$ & $1.399,99$ & $1.834,40$ & $2.459,60$ & $2.746,50$ & $2.324,00$ \\
\hline Honorários Advocatícios & 0,00 & 0,00 & 0,00 & $1.200,00$ & 0,00 & 0,00 & 0,00 & 0,00 & 0,00 & 0,00 & 0,00 & 0,00 \\
\hline Honorários Contábeis & $1.244,50$ & $1.244,50$ & $2.140,40$ & $1.244,50$ & $1.244,50$ & $1.186,40$ & $1.244,50$ & $1.244,50$ & $1.244,50$ & $1.307,19$ & $1.307,19$ & $1.307,19$ \\
\hline Pagamento Outras Unidades & $1.339,00$ & 390,00 & 224,00 & 0,00 & 0,00 & 0,00 & 0,00 & 0,00 & 0,00 & 150,00 & 214,00 & 189,00 \\
\hline Papelaria & 129,79 & 100,00 & 120,00 & 77,21 & 30,00 & 100,00 & 129,40 & 20,00 & 50,90 & 0,00 & 43,10 & 40,00 \\
\hline Taxas Diversas & 479,10 & 705,81 & $1.622,33$ & 688,24 & $1.179,33$ & 388,36 & $1.774,07$ & $1.011,99$ & $2.685,26$ & $2.352,17$ & $2.371,32$ & $2.970,27$ \\
\hline Sistema Eleve & 166,50 & 181,50 & 153,00 & 202,50 & 210,00 & 214,50 & 204,00 & 210,00 & 208,50 & 226,50 & 255,99 & 252,77 \\
\hline Despesas Diversas & 327,80 & 531,86 & 211,80 & 122,80 & 0,00 & $1.093,74$ & $2.268,23$ & 0,00 & 385,15 & 507,70 & 100,00 & 761,24 \\
\hline Total ............................. & $13.806,17$ & $15.608,88$ & $14.783,52$ & $11.845,24$ & $14.440,58$ & $14.195,75$ & $21.057,55$ & $16.219,26$ & $14.818,77$ & $14.734,56$ & $16.778,01$ & $21.778,85$ \\
\hline
\end{tabular}

Fonte: Dados da pesquisa (2020)

Com base nos dados das Tabelas 5 e 6 , as despesas administrativas totalizaram no período o valor de $\mathrm{R} \$ 122.720,25$; e as despesas operacionais um montante de $\mathrm{R} \$ 1$ 190.067,14, de maio/2018 a abril/2019. Contando com esses dados, com a margem de contribuição total, registrada na Tabela 3, e com o total de alunos frequentes no período, foi possível calcular o Ponto de Equilíbrio total e por turma da escola, Tabelas 7 e 8, respectivamente.

Tabela 7

Ponto de equilíbrio total da escola - maio/2018 a abril/2019

\begin{tabular}{l|r}
\hline \multicolumn{1}{c|}{ Itens } & \multicolumn{1}{c}{ Valor - R\$ } \\
\hline Despesas Administrativas & $122.720,25$ \\
Despesas Operacionais & $190.067,14$ \\
Despesas Financeiras & 0,00 \\
\hline = Gastos totais mensais da escola = a & $312.787,39$ \\
\hline Margem de Contribuição = b & $428.782,41$ \\
Total de mensalidades vendidas = c & 1.697 \\
\hline = Ponto de Equilíbrio em mensalidades (a/(b/c) & 1.238 \\
\hline
\end{tabular}

Fonte: Dados da pesquisa (2020).

Ao dividir os gastos fixos ( $\mathrm{R} \$ 312.787,39)$, realizados pela escola entre maio/2018 a abril/2019, pelo resultado da divisão do valor da margem de contribuição total ( $\mathrm{R} \$ 428.782,41)$ pela quantidade vendida de alunos regulares (1.697), apurou-se que a entidade precisava ter frequentemente estudando, no período, 1.238 alunos para alcançar o ponto de equilíbrio contábil, que equivale a não ter lucro e nem incorrer em prejuízo (Tabela 7).

Os valores individualizados dos pontos de equilíbrio, considerando as quatro turmas que a escola, são evidenciados na Tabela 8. 
Tabela 8

Ponto de equilíbrio por turma - maio/2018 a abril/2019

\begin{tabular}{l|c|r|c|c|r}
\hline \multicolumn{1}{c|}{ Turma } & $\begin{array}{c}\text { Quantidade } \\
\text { Alunos }\end{array}$ & \% do Total & PE por Aluno & $\begin{array}{c}\text { Mensalidade por } \\
\text { aluno (R\$) }\end{array}$ & \multicolumn{1}{c}{$\begin{array}{c}\text { PE em Valor } \\
\text { (R } \$)\end{array}$} \\
\hline Adults + Hyper & 827 & $48,73 \%$ & 603,28 & 311,50 & $187.921,23$ \\
Adults & 736 & $43,37 \%$ & 536,90 & 311,50 & $167.243,07$ \\
Hyper & 50 & $2,95 \%$ & 36,47 & 255,58 & $9.322,00$ \\
Teens & 84 & $4,95 \%$ & 61,28 & 251,50 & $15.410,95$ \\
\hline Total & 1.697 & $100,00 \%$ & 1.238 & & $379.897,26$ \\
\hline
\end{tabular}

Fonte: Dados da pesquisa (2020).

Após, apurado o percentual de cada turma no número total de alunos. Tal percentual foi aplicado sobre o valor total do ponto de equilíbrio (1.238 alunos) para se determinar o volume necessário de alunos que cada turma deveria ter para que a escola atingisse o ponto de equilíbrio. Em seguida, multiplicou-se esse ponto de equilíbrio, de cada turma, pelo valor da mensalidade das respectivas turmas.

Com isso, foi calculado o ponto de equilíbrio em valor monetário ( $\mathrm{R} \$$ ) de cada uma das 4 turmas no período, cujo total da escola chegou a $\mathrm{R} \$ 379.897,26$. Ou seja, a empresa analisada precisaria faturar esse montante para ter resultado nulo entre os meses de maio/2018 a abril/2019.

Com os dados que foram calculados na Tabela 8 e com a quantidade de alunos matriculados em cada turma da escola, realizou-se o cálculo da Margem de Segurança (Tabela 9). A margem de segurança em mensalidade das turmas foi apurada subtraindo-se da quantidade de mensalidade o ponto de equilíbrio em mensalidade, gerando margem de segurança em mensalidade total de 459,08.

Tabela 9

Margem de segurança - maio/2018 a abril/2019

\begin{tabular}{l|c|r|r|r|r}
\hline \multicolumn{1}{c|}{ Turma } & $\begin{array}{c}\text { Quantidade de } \\
\text { Mensalidades }\end{array}$ & $\begin{array}{c}\text { Ponto de } \\
\text { Equilíbrio em } \\
\text { Mensalidade }\end{array}$ & $\begin{array}{c}\text { Margem de } \\
\text { Segurança em } \\
\text { Mensalidade }\end{array}$ & $\begin{array}{c}\text { Mensalidade } \\
\text { unitária } \\
\text { (R\$) }\end{array}$ & $\begin{array}{c}\text { Margem de } \\
\text { Segurança em } \\
\text { Valor (R\$) }\end{array}$ \\
\hline Adults + Hyper & 827 & 603,28 & 223,72 & 311,50 & $69.689,27$ \\
Adults & 736 & 536,90 & 199,10 & 311,50 & $62.020,93$ \\
Hyper & 50 & 36,47 & 13,53 & 255,58 & $3.457,00$ \\
Teens & 84 & 61,28 & 22,72 & 251,50 & $5.715,05$ \\
\hline Total.... & 1.697 & 1.238 & 459,08 & & $140.882,24$ \\
\hline
\end{tabular}

Fonte: Dados da pesquisa (2020).

Em seguida, multiplicou a margem de segurança em mensalidades de cada turma pelo respectivo preço da mensalidade unitário $(\mathrm{R} \$)$, o que evidenciou o valor da margem de segurança em valor monetário $(\mathrm{R} \$)$ das turmas, na qual o valor total da escola foi de $\mathrm{R} \$ 140.882,24$. Com isso, assume-se, que o faturamento da escola poderia reduzir-se até esse valor que não ocasionaria prejuízo para a instituição.

O estudo estruturou Demonstrações de Resultado quadrimestrais, no período de maio/2018 a abril/2019 foram separados em 3 quadrimestres. Os resultados do período de maio a agosto de 
2018 indicaram que a escola contabilizou lucro no período de $\mathrm{R} \$ 44.903,31$, alcançando taxa de lucratividade de $28,48 \%$, em relação ao total das receitas.

O ponto de equilíbrio total foi calculado utilizando-se a soma das despesas administrativas, orçamentarias e financeiras dividido pelo percentual da margem de contribuição ( $\mathrm{R} \$ 103.130,15)$, a margem de segurança decorreu do valor de vendas no período menos o ponto de equilíbrio ( $\mathrm{R} \$ 54.542,45)$ e o grau de alavancagem operacional deu-se da divisão da margem de contribuição pelo resultado do período $(2,89)$.

Entre os meses de setembro e dezembro/2019 houve um decréscimo no resultado do período ( $\mathrm{R} \$ 26.255,21)$, em comparação aos quatro meses anteriores. A taxa de lucratividade da escola também sofreu uma redução, no $2^{\circ}$ quadrimestre analisado, terminando os quatro meses com um percentual de $15,31 \%$.

Em contrapartida o ponto de equilíbrio sofreu um aumento, totalizando o valor de $\mathrm{R} \$ 139.612,07$. O saldo da margem de segurança terminou em $\mathrm{R} \$ 31.885,79$, um valor inferior ao do quadrimestre anterior. $\mathrm{O}$ valor do grau de alavancagem operacional terminou em alta $(5,38)$, quando comparado com o $1^{\circ}$ quadrimestre.

O resultado do terceiro quadrimestre foi de $\mathrm{R} \$ 44.836,50$, um valor superior ao quadrimestre anterior e equivalente ao $1^{\circ}$ quadrimestre da série pesquisada. $O$ percentual de lucratividade da escola foi de $23,40 \%$. O ponto de equilíbrio teve um aumento em relação aos meses anteriores, terminando com um valor de $\mathrm{R} \$ 137.152,78$. O valor da margem de segurança e do grau de alavancagem operacional foi de $\mathrm{R} \$ 54.456,26$ e 3,52, respectivamente.

A demonstração do resultado, referente a todo o período analisado, maio/2018 a abril/2019, está retratada na Tabela 10.

Tabela 10

Demonstração do Resultado - maio/2018 a abril/2019

\begin{tabular}{l|r|r}
\hline \multicolumn{1}{c|}{ Itens } & \multicolumn{1}{c}{ Total } & \multicolumn{1}{c}{$\%$} \\
\hline (+) Vendas do período & $520.779,50$ & $100,00 \%$ \\
(-) Tributos sobre vendas & $10.415,59$ & $2,00 \%$ \\
(-) Material escolar & $81.581,50$ & $15,67 \%$ \\
\hline (=) Margem de contribuição total & $\mathbf{4 2 8 . 7 8 2 , 4 1}$ & $\mathbf{8 2 , 3 3 \%}$ \\
\hline (-) Despesas administrativas & $122.720,25$ & $23,56 \%$ \\
(-) Despesas operacionais & $190.067,14$ & $36,50 \%$ \\
(-) Despesas financeiras & 0,00 & \\
\hline (=) Resultado do período & $\mathbf{1 1 5 . 9 9 5 , 0 2}$ & $\mathbf{2 2 , 2 7 \%}$ \\
\hline (=) Ponto de Equilíbrio & $379.897,26$ & \\
\hline (=) Margem de Segurança & $140.882,24$ & \\
\hline (=) Grau de Alavancagem Operacional & 3,70 & \\
\hline
\end{tabular}

Fonte: Dados da pesquisa (2020).

O resultado referente a margem de contribuição de todos os meses analisados chegou a um valor de $\mathrm{R} \$ 428.782,41$. O valor do resultado líquido do período foi de $\mathrm{R} \$ 115.995,02$, descontados as despesas administrativas, operacionais e financeiras. $O$ percentual de lucratividade sobre as vendas foi de $22,27 \%$. O ponto de equilíbrio registrado terminou com um valor de $\mathrm{R} \$ 379.897,26$ e a margem de segurança $\mathrm{R} \$ 140.882,24$. O grau de alavancagem operacional encerou o período com 3,70. 
As últimas informações das análises realizadas se referem ao desempenho por turmas, por meio da Margem de Contribuição (MC), e seus resultados constam da Tabela 11. A Tabela foi preenchida com base nos valores da Tabela 4. Foram calculados os percentuais das vendas de cada turma, na qual utilizou-se o valor de venda de cada turma dividido pelo valor total de vendas.

Tabela 11

Desempenho por turma - maio/2018 a abril/2019

\begin{tabular}{l|r|c|r|c}
\hline Turma & Vendas em R\$ & \% das Vendas & MC Total em R\$ & $\%$ da MC Total \\
\hline Adults + Hyper & $257.610,50$ & $49,47 \%$ & $211.108,29$ & $49,23 \%$ \\
Adults & $229.264,00$ & $44,02 \%$ & $187.878,72$ & $43,82 \%$ \\
Hyper & $12.779,00$ & $2,45 \%$ & $10.981,92$ & $2,56 \%$ \\
Teens & $21.126,00$ & $4,06 \%$ & $18.813,48$ & $4,39 \%$ \\
\hline Totais ......... & $520.779,50$ & $100,00 \%$ & $428.782,41$ & $100,00 \%$ \\
\hline
\end{tabular}

Fonte: Dados da pesquisa (2020).

Após calcular o percentual das vendas, calculou-se o percentual da margem de contribuição, dividindo o valor MC em $\mathrm{R} \$$ de cada turma pelo total MC em $\mathrm{R} \$$. Esses resultados indicam que as turmas Adults + Hyper e a Adults, são que mais contribuem para o montante de receitas da escola e, consequentemente, também são as que mais contribuem para com a lucratividade da empresa.

\section{CONSIDERAÇÕES FINAIS}

O objetivo da presente pesquisa foi aplicar os procedimentos da análise de Custo/Volume/Lucro em um empreendimento que explora a educação de idiomas, mais especificamente, o inglês. Buscou-se identificar quais as informações de caráter gerencial tais aplicação pode oferecer aos administradores da empresa.

O período de análise foi de 12 meses, e englobou o período de maio/2018 a abril/2019, uma questão importante a salientar foi a quantidade de informações geradas pelo estudo sobre a organização analisada. Essa gama de informações propiciou que a pesquisa destacar os seguintes aspectos qualitativos e quantitativos resultantes da aplicação da análise CVL em uma escola de idiomas: (1) Margem de contribuição por aluno, em cada turma, assim como margem de contribuição total por turma; (2) Ponto de equilíbrio por turma e o ponto de equilíbrio total da escola; (3) Margem de segurança; (4) Grau de alavancagem operacional.

As turmas Adults + Hyper e Adults foram as que registraram maiores margens de contribuição, ambas, com $\mathrm{R} \$ 255,27$. Entretanto, quanto à margem de contribuição em \%, a turma Teens foi a que apresentou maior percentual 89,05\%, seguida da Hyper com 85,94 e pôr fim a Adults + Hyper e a Adults com $81,95 \%$. A margem de contribuição por turma no final do período analisado gerou um resultado de $\mathrm{R} \$ 428.782,41$.

Diante da margem de contribuição total das quatro turmas de $\mathrm{R} \$ 428.782,41$, calculou-se a participação percentual de cada uma das turmas para formar esse montante. Constatou-se que as turmas com as maiores quantidades de alunos são as que mais contribuem para o montante 
total, ou seja, a Adults + Hyper contribuiu com 49,23\% da margem de contribuição total e a Adults com 43,82\%, juntas totalizaram $93,05 \%$ do montante total.

Os cálculos do envolvendo o ponto de equilíbrio indicaram que a escola precisou no período de 1.238 alunos regulares para cobrir suas despesas e obter lucro. E a margem de segurança em alunos é de 459. A margem de segurança em valor foi de $\mathrm{R} \$ 140.882,24$, no período avaliado.

O resultado geral contabilizado, entre maio/2018 a abril/2019, evidenciou que as despesas administrativas e operacionais representaram $23,56 \%$ e $36,50 \%$, respectivamente, do total das receitas do período, e o lucro auferido neste um ano foi de 22,27 das vendas realizadas.

Este estudo baseou-se na pesquisa da Wernke, Faccenda e Junges (2017), desta forma, utilizamos os mesmos procedimentos de análises, nesse sentido, os dois estudos são similares. Entretanto, podemos destacar que a empresa analisada neste estudo possui 4 grupos turmas enquanto no outro haviam 15 grupos; outra diferença evidenciada nas análises é que as turmas com alunos adultos são as que mais contribuíam para o resultado total da escola pesquisada; também, o período estudado, o que realizamos englobou 12 meses e o estudo de referência utilizou 1 mês de análise.

Considera-se que essa pesquisa pode ter contribuições tanto práticas quanto teóricas. No que se refere a teoria essa pesquisa demonstra a aplicabilidade da análise custo/volume/lucro em uma escola de idiomas, mostrando assim que a ferramenta pode ser aplicada em instituições de ensino de maior ou menor porte. No âmbito prático esse estudo mostra as formas da aplicação da análise CVL em uma escola de idiomas gerando informação que podem servir de auxílio tanto para empresários e administradores de outras escolas. Ressalta-se, porém, que por tratarse de estudo de caso os achados desta pesquisa referem-se à organização estudada, não sendo possível a generalização destes.

Sob a perspectiva de estudos futuros sugere a aplicação da análise custo/volume/lucro junto a empresas prestadoras de serviços que tenham outras atividades econômicas, como: academias, creches etc., com o objetivo de aumentar a discussão sobre a aplicabilidade dessa ferramenta de cunho gerencial.

\section{REFERÊNCIAS}

Atkinson, A. A., Banker, R. D, Kaplan; R. S., \& Young, S. M. (2000). Contabilidade gerencial. São Paulo: Atlas.

Bornia, A. C. (2010). Análise gerencial de custos. São Paulo: Atlas.

Crepaldi, S. A. (2010). Curso básico de contabilidade de custos. 5. ed. São Paulo: Atlas.

Dalmácio, F. Z., Rangel, L. L., Lopes, V. A., \& Teixeira, A. J. C. (2013). Custo-volume-lucro como ferramenta de gestão em uma empresa de serviços. ABCustos, 8 (1), 129-149.

Durieux, A., Beuren, I. M., Sousa, M. A. B., \& Raupp, F. M. (2003, outubro). Proposta de sistema de custos para uma escola franqueada de idiomas: o caso da escola de idiomas Fisk. Anais Congresso Brasileiro de Custos, Guarapari, ES, Brasil, 10. Recuperado de https://anaiscbc.emnuvens.com.br/anais/article/view/2562/2562. 
Estadão. (2017, junho 22). O ensino da língua inglesa no Brasil. Portal Jornal Estado de São. Recuperado de: https://educacao.estadao.com.br/blogs/cambridge-english/o-ensinoda-lingua-inglesa-no-brasil/. Blog dos colégios - Cambridge English.

Ferronatto, J. C. (2014). A análise da relação custo $x$ volume x lucro: estudo de caso em uma instituição de ensino. (Dissertação de Mestrado). Escola de Administração, Universidade Federal do Rio Grande do Sul, Porto Alegre, RS, Brasil.

Gama, E. S., Jesus, L. G., Loureiro, N. C. F., Silva, D. A. S., \& Xavier, I. C. (2019, novembro). Análise CVL aplicada a uma escola prestadora de serviços de ensino profissionalizante no município de Marabá, Estado do Pará. Anais do Simpósio de Engenharia de Produção de Sergipe, São Cristóvão, SE, Brasil, 11. Recuperado de https://ri.ufs.br/bitstream/riufs/12554/2/AnaliseCVLaplicada.pdf

Garrison, R.; H., \& Noreen, E. W. (2001). Contabilidade gerencial. Rio de Janeiro: LTC.

Gil, A. C. (2008). Métodos e técnicas de pesquisa social. 6. Ed. São Paulo: Atlas.

Horngren, G. T., Foster, G., \& Datar, S. M. (2004). Contabilidade de custos: uma abordagem gerencial. 11.ed. São Paulo: Prentice Hall.

Machuga, S. (2012). A case method approach to teaching cost-volume-profit analysis. Journal of Accounting and Finance, 12 (5), 104-109.

Maher, M. (2001). Contabilidade de custos: criando valor para a administração. São Paulo: Atlas.

Mantovani, F. R. (2016). Precificação de cursos em escolas de idiomas: desenvolvimento de uma aplicação baseada no custeio por atividade. Práticas em Contabilidade e Gestão, 4 (1), 281-299.

Marion, J. C. (2009). Contabilidade empresarial. 15 ed. São Paulo: Atlas.

Martins, E. (2010). Contabilidade de custos. 10. ed. São Paulo: Atlas.

Matarazzo, D. C. (2003). Análise financeira de balanços: abordagem básica e gerencial. 6 ed. São Paulo: Atlas.

Megliorini, E. (2011). Custos análise e gestão. 3. ed. São Paulo: Pearson Prentice Hall.

Perez, J. H., Jr., Oliveira, L. M., \& Costa, R. G. (2003). Gestão estratégica de custos. 3. ed. São Paulo: Atlas.

Padoveze, C. L. (2005). Curso básico gerencial de custos. São Paulo: Pioneira Thomson Learning.

Padoveze, C. L. (2011). Contabilidade empresarial e societária. São Paulo: Saraiva.

Santos, J. J. (2011). Contabilidade e análise de custos. 6 ed. São Paulo: Atlas.

Santos, L. I. S. (2005). Crenças acerca da inclusão de língua inglesa nas séries iniciais. 232, p. (Dissertação). Mestrado. Universidade Federal de Mato Grosso.

Warren, C. S., Reeve, J. M., \& Fees, P. E. (2001). Contabilidade gerencial. 2.ed. São Paulo: Pioneira Thomson Learning.

Wernke, R. (2010). Análise de custos e preços de venda: ênfase em aplicações e casos nacionais. São Paulo: Saraiva.

Wernke, R., Faccenda, L. S., \& Junges, I. (2017, novembro). Análise Custo/Volume/Lucro Aplicada em Escola de Idiomas. Anais do Congresso Brasileiro de Custos, Florianópolis, SC, Brasil, 24. Recuperado de https://anaiscbc.emnuvens.com.br/anais/article/view/ $4287 / 4287$ 